DOI: http://dx.doi.org/10.18764/2358-4319.v9n3p133-155.

\title{
EDUCAÇÃO DE JOVENS E ADULTOS NO CAMPUS PELOTAS DO IFSUL: entre o proposto e o realizado
}

\author{
Juliana Roldão Bittencourt ${ }^{1}$ \\ Márcia Helena Guimarães Sauaia Rostas ${ }^{2}$ \\ Maria Cecília Pereira Isaacsson ${ }^{3}$
}

\section{RESUMO}

O presente artigo objetiva analisar o cumprimento da proposta de Educação de Jovens e Adultos dentro do Programa Nacional de Integração da Educação Profissional com a Educação Básica, no Campus Pelotas do Instituto Federal sul-rio-grandense, bem como a avaliação das práticas, adotadas na instituição, durante a formação do estudante. A pesquisa é de cunho qualitativo exploratório, com nuances quantitativas, em relação à análise dos dados obtidos. Foram realizadas entrevistas com duas turmas de Proeja do curso técnico em Execução, Conservação e Restauro de Edificações, nas quais foram analisadas questões como o sentimento e a expectativa desses alunos em relação ao curso e ao ambiente escolar, e se essas expectativas foram atendidas ao longo do período.

Palavras-chave: Proeja. Práticas pedagógicas. Educação profissional.

1 Mestranda em Educação e Tecnologia pelo Instituto Federal de Educação, Ciência e Tecnologia sul-rio-grandense (IFSul). E-mail: jullibitencourt@gmail.com.

2 Professora adjunta do Departamento de Graduação e Pós-Graduação Programa de Mestrado Profissional em Educação e Tecnologia do IF-Sul, Campus Pelotas. Doutora pela Universidade Estadual Paulista Júlio de Mesquita Filho (UNESP). Pesquisadora do GP em Fonologia do Português: Arcaico \& Brasileiro (UNESP) e GP em Linguagens Verbais, Visuais e Tecnologia (IFSul).E-mail: mrostas@hotmail.com.

3 Mestranda em Educação e Tecnologia pelo IFSul. E-mail: isaacsson@hotmail.com. 


\section{YOUTH AND ADULT EDUCATION ON IFSUL CAMPUS IN PELOTAS:}

between the proposed and the accomplished

\section{ABSTRACT}

This article aims to analyze the fulfillment of the proposed Youth and Adult Education within the National Professional Education Program Integration with Basic Education, on the Campus in Pelotas of Instituto Federal sul-rio-grandense, as well as and the evaluation of the practices adopted by the institution, throughout the formation of the student. The research follows a qualitative approach, with quantitative touch in relation to data analysis. There were made interviews with two groups of Proeja from technical course in Execution, Conservation and Restoration of Buildings, in which there were analyzed feelings and expectations of these students towards the course and the school environment, and if those expectations were met over the period of time.

Keywords: Proeja. Pedagogical practices. Professional education.

\section{EDUCACIÓN DE JÓVENES Y ADULTOS EN EL CAMPUS PELOTAS DEL IFSUL: entre lo propuesto y lo realizado}

\section{RESUMEN}

El presente artículo tiene por objetivo analizar el cumplimiento de propuestas de Educación de Jóvenes y Adultos dentro del Programa Nacional de Integración Profesional con la Educación Básica, en el Campus Pelotas del Instituto Federal sur-rio-grandense, bien como la evaluación de las prácticas, adoptadas en la institución, durante la formación de los estudiantes. La investigación es de modelo cualitativo exploratorio, con matices cuantitativas, en relación al análisis de los datos obtenidos. Fueron realizadas entrevistas con dos clases de Proeja del curso técnico en Ejecución, Conservación y Restauro de Edificaciones, en las cuales fueron analizadas cuestiones como el sentimiento y expectativa de estos alumnos en relación al curso y el ambiente escolar, y si estas expectativas fueron atendidas a lo largo del período.

Palabras claves: Proeja. Practicas pedagógicas. Educación Profesional. 


\section{Introdução}

A temática da Educação de Jovens e Adultos (EJA) suscita, em si, questões muito complexas. Para fundamentar essa abordagem, é necessário trazer elementos importantes de sua trajetória políticopedagógica e compreender o contexto histórico (movimentos sociais e políticos) do Brasil na época de sua implementação. É importante, ainda, desprender a visão tradicional e homogênea que se pauta pela mera transmissão de conhecimentos e permeia, ainda, muitos cotidianos e currículos escolares, a fim de conseguir estabelecer novos olhares sobre essa modalidade de educação, seus contextos e desdobramentos.

$\mathrm{O}$ artigo em questão discorre sobre a trajetória histórica da Educação de Jovens e Adultos (EJA), desde seu surgimento até sua implementação dentro do Programa Nacional de Integração da Educação Profissional com a Educação Básica (Proeja), no Campus Pelotas do Instituto Federal sul-rio-grandense (IFSul). Com base nestes dados, intenta verificar como vem se estruturando o curso técnico em Execução, Conservação e Restauro, tendo como fundamento o seu Projeto Político Pedagógico (PPP) no que se refere aos objetivos gerais, a partir do olhar do estudante.

\section{O percurso histórico da EJA no Brasil}

Inicia-se pela década de 1930, marcada por diversas mudanças no cenário brasileiro. Um período que deu "[...] início [a] uma etapa decisiva na reformulação do poder público no Brasil" (BEISIEGEL, 1989, p. 7). Contudo, destaca-se aqui apenas as mudanças cujas implicações ocasionaram em modificações para os processos educacionais.

A expansão do capitalismo e um processo de crescente industrialização e urbanização das cidades ocasionaram uma forte necessidade de mão de obra barata. Entretanto, as taxas de analfabetismo e o difícil acesso das camadas mais baixas da população aos bancos escolares representaram obstáculos ao longo deste processo. 
Dentro deste contexto, o governo brasileiro, pressionado pela necessidade de capacitar, ainda que "minimamente", a população mais carente para o trabalho toma medidas para ampliar as vagas e o acesso dessa população à educação. A administração pública viabilizou a evolução das escolas secundárias movida por questões muito mais políticas do que educacionais. No entanto, os resultados de toda essa mobilização deixaram diversas marcas e mudanças no cenário educacional da época (BEISIEGEL, 1989).

A Constituição Federal de 1934 representou um marco importante, já que, por meio dela, o Estado firmou seu compromisso com a educação, bem como assegurou a fixação de um plano nacional, no qual se deveriam cumprir diversas normas, dentre elas o ensino primário integral gratuito e extensivo aos adultos, conforme dispõe o artigo 150, parágrafo único, alínea "a" (BRASIL, 1934).

Salienta-se que, na época em que foi arrazoada a referida Constituição, a preocupação era a de resguardar um capítulo para tratar especificamente da educação e da cultura, o que demonstra a inquietação sobre o "alcance" da educação desde então.

Em 1937, foi criado o Estado Novo pelo governo de Getúlio Vargas, que se estendeu até outubro de 1945 (HENN; NUNES, 2013). Nesse período, o papel centralizador do Estado teve grande influência sobre a educação, mantendo-se os princípios "desenvolvimentistas" e "nacionalistas", sob a marca de uma forte industrialização, mesmo após a transição do Estado Novo, para a ordem republicana (BEISIEGEL, 1989).

Já em 1947, o Ministério da Educação e Saúde passou a promover a Campanha de Educação de Adolescentes e Adultos (CEAA), cujo objetivo principal era levar a educação de base a todos os brasileiros analfabetos, tanto das cidades quanto das áreas rurais (BEISIEGEL, 1989).

A questão deveria ir muito além do que apenas alfabetizar adultos, mas capacitá-los a contribuir para seu "ajustamento social", ou seja, uma educação que cumpra determinadas finalidades, elencadas pelo Estado: “[...] suas origens ideológicas e suas funções de 'controle 
social' ou, em outras palavras, suas dimensões políticas, no sentido mais amplo do conceito" (BEISIEGEL, 1989, p. 7).

$\mathrm{Na}$ época, o processo educacional possuía um caráter muito mais quantitativo do que qualitativo. Ressalta-se que nas décadas de 50 e 60 houve uma forte atuação de movimentos sociais no país, os quais imprimiram suas marcas e influenciaram também a atuação dos governantes da época (FÁVERO, 2006). Como exemplos, podem ser citados movimentos como o de Cultura Popular e o de Educação de Base, entre outros, que foram decisivos para a defesa das classes menos favorecidas e para a conscientização social, buscando não apenas a alfabetização, mas a formação de um cidadão crítico e consciente de si e da realidade a sua volta.

Conforme Gaspar (2009), o Movimento de Cultura Popular (MCP) foi criado em maio de 1960 e se tratava de uma instituição sem fins lucrativos, sendo influenciado principalmente por obras e autores franceses. Suas atividades possuíam o condão de conscientizar as massas por meio da alfabetização e educação de base.

De acordo com Fávero (2006), o Movimento Educação de Base (MEB) foi criado em 1961, com o apoio do Governo Federal, e tinha a finalidade de desenvolver programa de alfabetização e educação de base, por meio de escolas radiofônicas, a partir de emissoras católicas. Decorridos dois anos de atuação, com alteração radical dos seus objetivos e métodos de ação, houve a aliança com outros movimentos de cultura popular do período. Com interrupções e refluxos, o MEB existe até hoje, tentando fazer ressurgir seu modo de atuação original.

Em dezembro de 1961, com a aprovação da primeira Lei de Diretrizes e Bases da Educação Nacional (LDB), o Estado passou a se comprometer de maneira mais efetiva com a educação, uma vez que assegura o direito a ela por meio da "[...] obrigação do poder público [...] de ministrarem o ensino em todos os graus, na forma de lei em vigor" e ainda "[...] pela obrigação do Estado de fornecer recursos indispensáveis [...] de modo que sejam asseguradas iguais oportunidades a todos" (BRASIL, 1961, n.p.). 
Após, em 1964, foi instituído o Programa Nacional de Alfabetização, também por meio de iniciativas do Ministério da Educação. O programa, destinado à parcela iletrada da população brasileira, utilizava o método Freireano, partindo da realidade do povo e de seu cotidiano, atribuindo significado real e consistente ao que estava sendo ensinado, facilitando o processo de ensino-aprendizagem (FÁVERO, 2006).

No ano de 1968, foi implantado pelo governo o Movimento Brasileiro de Alfabetização (Mobral), cujo principal objetivo era alfabetizar e propiciar condições de aquisição das técnicas de leitura e escrita, além da aprendizagem de cálculos matemáticos para os adultos acima da idade escolar tida como "normal". O Mobral teve fim em 1985, devido à falta de recursos, em função do período de recessão da década de 1980 (PAIVA, 2003).

Após o ano de 1988, já promulgada a nova Constituição Brasileira, foi marcado outro passo importante para a EJA, pois em seu artigo de $n^{\circ} 208$, inciso I, o documento garante, dentre os deveres do Estado, a: "[...] educação básica obrigatória e gratuita dos 4 (quatro) aos 17 (dezessete) anos de idade, assegurada inclusive sua oferta gratuita para todos os que a ela não tiveram acesso na idade própria" (BRASIL, 1988, n.p.).

Por meio da Carta Magna, ao apontar a obrigatoriedade de garantia do acesso a todos, inclusive aos que não puderam fazê-lo em idade própria, o Estado se compromete de forma mais direta com a oferta de educação para o público de jovens e adultos e propicia que outros avanços continuem ocorrendo.

Quase uma década depois, em 1996, é aprovada a LDB, na qual o Poder Público volta a reafirmar o direito de acesso à educação para os jovens e adultos, quando menciona em seu artigo de $n^{\circ} 37$, inciso l, que

os sistemas de ensino assegurarão gratuitamente aos jovens e aos adultos, que não puderam efetuar os estudos na idade regular, oportunidades educacionais apropriadas, consideradas as características do alunado, seus interesses, 
condições de vida e de trabalho, mediante cursos e exames (BRASIL, 1996, n.p.).

Em decorrência das afirmações legais ratificadas pela LDB de 1996, que passa a reconhecer a EJA como uma modalidade de educação básica nas etapas do ensino fundamental e médio, a Câmara de Educação Básica (CEB) do Conselho Nacional de Educação (CNE) regulamentou no ano 2000 as Diretrizes Curriculares Nacionais para a EJA, pelo Parecer n ${ }^{\circ}$ $11 / 2000$, dando seguimento, dessa forma, a outro passo importante no atendimento dessas políticas educacionais (BRASIL, 2000).

Diante do exposto, entende-se que, ao longo da história, a EJA passou por diversos momentos cruciais e vem sendo trabalhada e remodelada com o passar dos anos e o cenário histórico e político, como foi possível verificar nesta seção.

\section{O trajeto da educação profissional e tecnológica à EJA no Campus Pelotas do IFSul}

A partir do histórico traçado na seção anterior sobre como vem se dando a trajetória da EJA no Brasil, pode-se delinear o percurso que vem sendo percorrido no Campus Pelotas do IFSul. Verifica-se agora o caminho, desde sua criação até os dias atuais, no que tange ao ensino técnico e à implementação das políticas de atendimento aos jovens e adultos pelo Proeja.

Conforme já explanado, a década de 1930 trouxe diversas mudanças ao cenário educacional brasileiro: "Foi um período de grande expansão do ensino industrial, impulsionada por uma política de criação de novas escolas industriais e introdução de novas especializações nas escolas existentes" (BRASIL, 2011, p. 4).

Foi um período em que aconteceu um avanço nacional significativo do ensino técnico, que havia sido criado e regulamentado pelo Decreto $n^{\circ} 7.566$, de 23 de setembro de 1909, pelo então presidente Nilo Peçanha. As escolas receberam o nome de Escolas de Aprendizes 
Artífices e eram destinadas ao ensino profissional, primário e gratuito, sendo mais tarde, em 1937, transformadas em Liceus Profissionais.

Tendo em vista que já havia uma escola para essa modalidade em Porto Alegre, capital do Rio Grande do Sul, o Instituto TechnicoProfissional (ITP), o Estado não recebeu nenhuma Escola de Aprendizes e Artífices. No interior do estado, na cidade de Pelotas, seguiam as discussões e mobilizações em prol da oferta de ensino técnico.

Então, em 1917, Pelotas recebeu a Escola de Artes e Officios, que foi considerada na época um "aparelho de regeneração social" (MEIRELES, 2007, p. 23), uma vez que se destinava mais especificamente a capacitar a classe operária. Após o término de sua construção, ela foi entregue ao poder municipal no ano de 1930, passando a se chamar Escola Technico-Profissional.

No ano de 1942, esta escola se tornou parte da antiga rede federal de ensino industrial e, a partir daí, passou a ser totalmente custeada pela União. Teve sua nomenclatura modificada várias vezes ao longo dos anos: Escola Técnica de Pelotas (ETP), Escola Técnica Federal de Pelotas (ETFPEL), Centro Federal de Educação Tecnológica (Cefet) e, por fim, Instituto Federal sul-rio-grandense (IFSul).

Integrante da rede federal de educação profissional e tecnológica, o IFSul foi criado mediante a Lei $\mathrm{n}^{\circ} 11.892$, de 29 de dezembro de 2008. Tem como característica principal a verticalização do ensino, bem como a oferta de educação profissional e tecnológica nos diferentes níveis e modalidades, articulando a educação superior, básica e tecnológica.

Apesar das diferentes trocas nominais pelas quais passou, a instituição esteve comprometida com a oferta de uma educação pública, gratuita e de qualidade, preferencialmente integrada à formação profissional. A partir do ano de 1998, passou a desenvolver projetos na área da EJA. O primeiro deles foi o Ensino Médio para Jovens e Adultos (EMA), cujo objetivo principal era atender à comunidade, possibilitandoIhe o acesso à educação básica. Foram abertas turmas de EMA para formar 
primeiramente os servidores da instituição que não possuíam o ensino médio e, em seguida, turmas para o público externo. Cabe registrar que o EMA, por ser um projeto piloto, não contemplava nenhuma formação profissional específica.

Com o intuito de atender a essa demanda de formação profissional e aos dispositivos legais, dentre eles o Decreto $n^{\circ} 5.840$, de 13 de julho de 2006, surge o Proeja.

Em 2007, foi implantado o curso técnico em Montagem e Manutenção de Computadores, o primeiro na modalidade. Logo após, o curso técnico em Execução, Conservação e Restauro de Edificações. Ambos foram criados visando atender à comunidade com a oferta de formação integrada (formação de nível médio junto à formação profissional), sob a proposta de capacitar o estudante e promover a sua inserção no mercado de trabalho, bem como sua emancipação enquanto sujeito e cidadão (IFSUL, 2013).

Destaca-se que, para a elaboração do currículo e da matriz curricular dos cursos de Proeja do Campus Pelotas do IFSul, foram realizadas reuniões entre os professores envolvidos no processo, além de pesquisas sobre quais as áreas de conhecimento técnico que deveriam ser levadas em conta, bem como o tipo de profissionais que se pretendia formar.

Neste contexto, propôs-se um currículo que se dispusesse a trabalhar não apenas questões políticas e sociais, mas também que partisse da realidade desses educandos, a fim de que pudesse fazer sentido a eles. Um currículo que levasse em conta suas vivências, suas experiências de mundo e que falasse, sobretudo, uma linguagem que esses alunos pudessem compreender, assim como menciona Freire (1996, p. 37):

Não é possível respeito aos educandos, à sua dignidade, a seu ser formando-se, à sua identidade fazendo-se, se não se levam em consideração às condições em que eles vêm existindo, se não se reconhece a importância dos "conhecimentos de 
experiência feitos" com que chegam à escola. $\mathrm{O}$ respeito devido à dignidade do educando não me permite subestimar, pior ainda, zombar do saber que ele traz consigo para a escola.

A reflexão sobre o currículo da EJA remete a percebê-lo de forma social e democrática, com o intuito de que os processos educativos nele envolvidos sirvam para a emancipação de sujeitos que possam assumir, de forma consciente, o seu papel na sociedade da qual fazem parte.

\section{A pesquisa e a metodologia: um percurso traçado}

No decorrer estudo, refletiu-se sobre algumas das questões que devem ser levadas em conta no currículo de uma escola que se propõe a trabalhar com o público da EJA. Utilizou-se como referencial teórico para essas reflexões as concepções apontadas por Lindeman (1926), as quais trazem alguns pressupostos-chave para a EJA, dentre os quais se destacam: a aprendizagem centrada na vida, isto é, no cotidiano daquele adulto que busca o espaço escolar; as suas experiências como fonte de aprendizagem e o respeito à singularidade de cada indivíduo, compreendendo e aceitando as diferenças.

Refletindo acerca destes pontos e percebendo que o currículo elaborado para a EJA deve, além de contê-las, articular-se ainda ao aspecto da formação profissional (Proeja), pensa-se em avaliar a aplicação daquilo que foi proposto a partir dos objetivos gerais elencados no projeto do curso técnico em Execução, Conservação e Restauro de Edificações do Campus Pelotas do IFSul (2013, p. 8):

Assegurar a jovens e adultos, excluídos do sistema formal de educação, uma oportunidade de Educação Profissional Técnica de Nível Médio numa área - a construção civil - reconhecida por possuir grande número de trabalhadores com baixa escolaridade;

Desenvolver um projeto pedagógico baseado numa concepção de educação capaz de colaborar na formação de um cidadão crítico, autônomo, 
com capacidade de ação social e de, a partir de seu trabalho, capacitado a construir sua própria emancipação.

Demarcado o recorte da investigação, se refletiu a respeito de qual metodologia de pesquisa seria utilizada. Escolheu-se, então, o método qualitativo, apesar de serem utilizadas também nuances quantitativas no que diz respeito aos percentuais apresentados em seção posterior.

Denzin e Lincoln (2006, p. 17), com relação ao método qualitativo, elucidam que "[...] é uma atividade situada que localiza o observador no mundo" e permite compreender as questões envolvidas no universo da pesquisa com maior profundidade. Ademais, na pesquisa qualitativa, pode-se apontar que "os métodos [...] são projetados para ajudar os pesquisadores a mergulhar no contexto da pesquisa e a compreender as teorias, as pessoas e os contextos sociais e culturais que envolvem a pesquisa" (DIAS; SILVA, 2010, p. 52).

No desenvolver da coleta de dados, foram utilizadas técnicas de pesquisa como observação participante e aplicação de um questionário (misto) junto às duas turmas do curso de Proeja, a fim de analisar questões como o sentimento e a expectativa dos alunos em relação ao curso e ao ambiente escolar, e se estas questões vinham sendo atendidas ao longo do período.

Os questionamentos, no instrumento de coleta, intentavam que o aluno fizesse uma reflexão acerca do que foi inicialmente proposto a eles por meio dos objetivos gerais traçados no projeto do curso técnico em Execução, Conservação e Restauro e se, de fato, estavam sendo levadas em consideração.

O instrumento da pesquisa foi aplicado em datas e horários agendados junto à coordenação do curso e com o devido consentimento dos professores e alunos. Participaram da pesquisa alunos de duas turmas (A e B) do curso ofertado no IFSul, em um total de 26 alunos, sendo 12 
da turma A e 14 da B. A amostra utilizada correspondeu à totalidade dos alunos matriculados e frequentes.

A contribuição dos sujeitos da investigação se deu pela resposta aos seguintes questionamentos: 1 - Como você se sente na escola? (Q1); 2 - Como você descreve sua relação com os professores? (Q2); 3 - Quando você tomou conhecimento desse curso, por que quis se matricular? (Q3); 4 - Você sente que o curso tem atendido às suas expectativas? Por quê? (Q4); 5 - O que você acredita que essa formação pode Ihe proporcionar? (Q5); 6 - Deixe-nos aqui suas sugestões de melhoria. (Q6).

Os dois primeiros questionamentos, caracterizado como do tipo fechado, continham opções de resposta em que o aluno deveria assinalar apenas uma delas. No que diz respeito à primeira pergunta, as opções de resposta eram: "Me sinto bem, faço parte desse campus"; "Me sinto bem, mas não me sinto integrado"; "Não me sinto à vontade, aqui não é pra mim"; "Nenhuma das alternativas acima. Como você se sente então?".

Já em relação ao segundo questionamento, as opções de resposta eram: "É boa. Tenho abertura e me sinto à vontade para partilhar questões e dilemas pessoais, se preciso for"; "É boa, contudo não me sinto muito à vontade"; "Não é nem boa, nem ruim. Mas gostaria de receber mais atenção"; "Tenho uma péssima relação"; "Nenhuma das alternativas acima. Descreva então.".

Com os resultados e dados coletados no instrumento aplicado, por meio das questões de número 1 e 2, constatou-se, em amplo aspecto, como vem se dando a relação destes alunos com a escola e com os professores. Nesta investigação, o conceito de "se sentir bem" no espaço escolar denotou questões como o sentimento de pertença, de fazer parte de determinado grupo e se sentir aceito nesse espaço. Quanto à questão do relacionamento com os professores, denotou a capacidade de interação social e a relação de confiança entre aluno/professor. 
As demais perguntas, que se caracterizaram como abertas, possuíam a finalidade de perceber o olhar do aluno sobre as suas expectativas durante e após o curso.

\section{Dos resultados obtidos à análise: um primeiro olhar}

A partir dos dados obtidos com o instrumento de coleta, os resultados apresentados neste artigo mapeiam um primeiro olhar sobre a questão e não esgotam todas as possibilidades de análise. Estão sujeitos a ajustes, (re)análises, bem como introdução de novas variáveis. Em uma primeira instância, será feito um apanhado quantitativo para, posteriormente, de posse deste, ter a análise qualitativa.

Quando os alunos foram questionados sobre seus sentimentos em relação à escola, eles responderam na seguinte proporção:

Gráfico 1: Resultado Q1.

\begin{tabular}{|cc|}
\hline 1,6 & 8,4 \\
\hline $\begin{array}{c}\text { 16\% sentem-se "bem", } \\
\text { integrados e parte da } \\
\text { comunidade acadêmica. }\end{array}$ & $\begin{array}{c}84 \% \text { sentem-se "bem", } \\
\text { mas não integrados à } \\
\text { comunidade acadêmica. }\end{array}$ \\
\hline
\end{tabular}

Fonte: própria pesquisa.

Ainda, quando questionados sobre sua relação com os professores, os alunos, em sua grande maioria, conforme gráfico abaixo, declararam ter uma boa relação, se sentem à vontade inclusive para partilhar questões e/ou dilemas pessoais. Os demais declararam ter uma boa relação, entretanto não se sentiam à vontade para pedir qualquer tipo de ajuda ou estabelecer relações mais próximas. 
Gráfico 2: Resultado Q2.

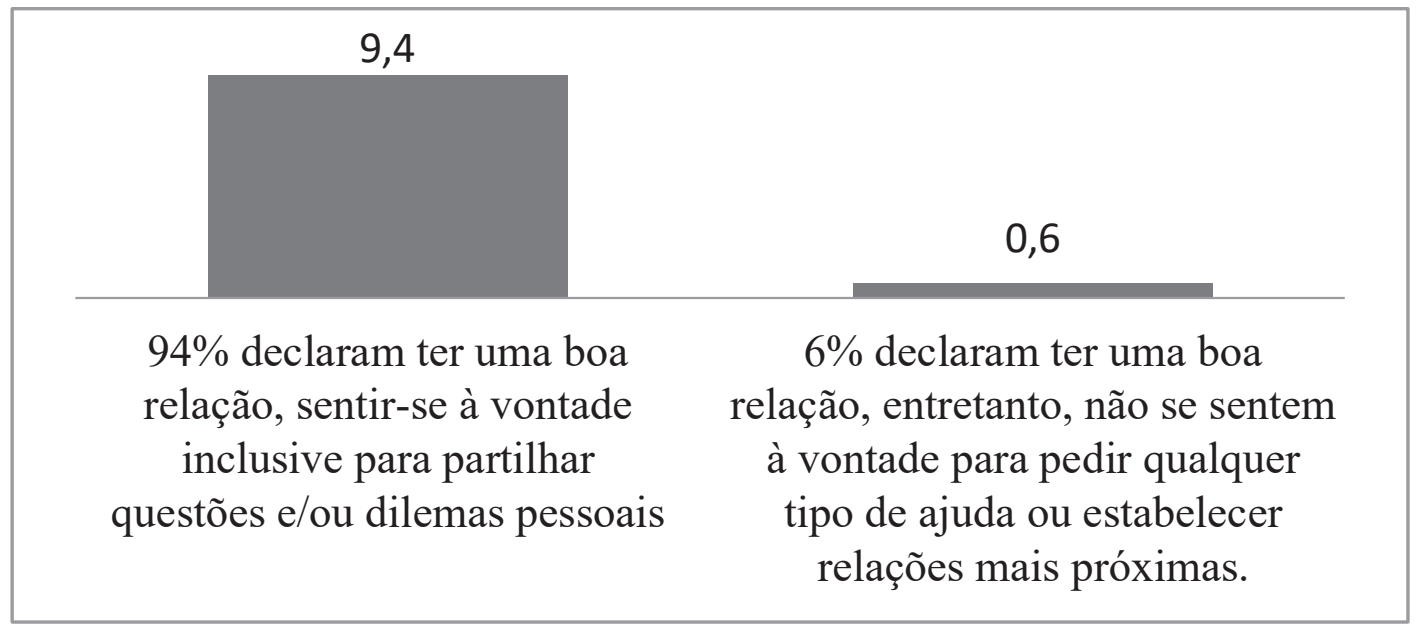

Fonte: própria pesquisa.

Em relação à questão de expectativas sobre o curso, ou seja, se ele atende ao que era esperado, observa-se um total de $63 \%$ de satisfação parcial e 37\% de satisfação plena, conforme os dados a seguir:

Gráfico 3: Resultado Q4.

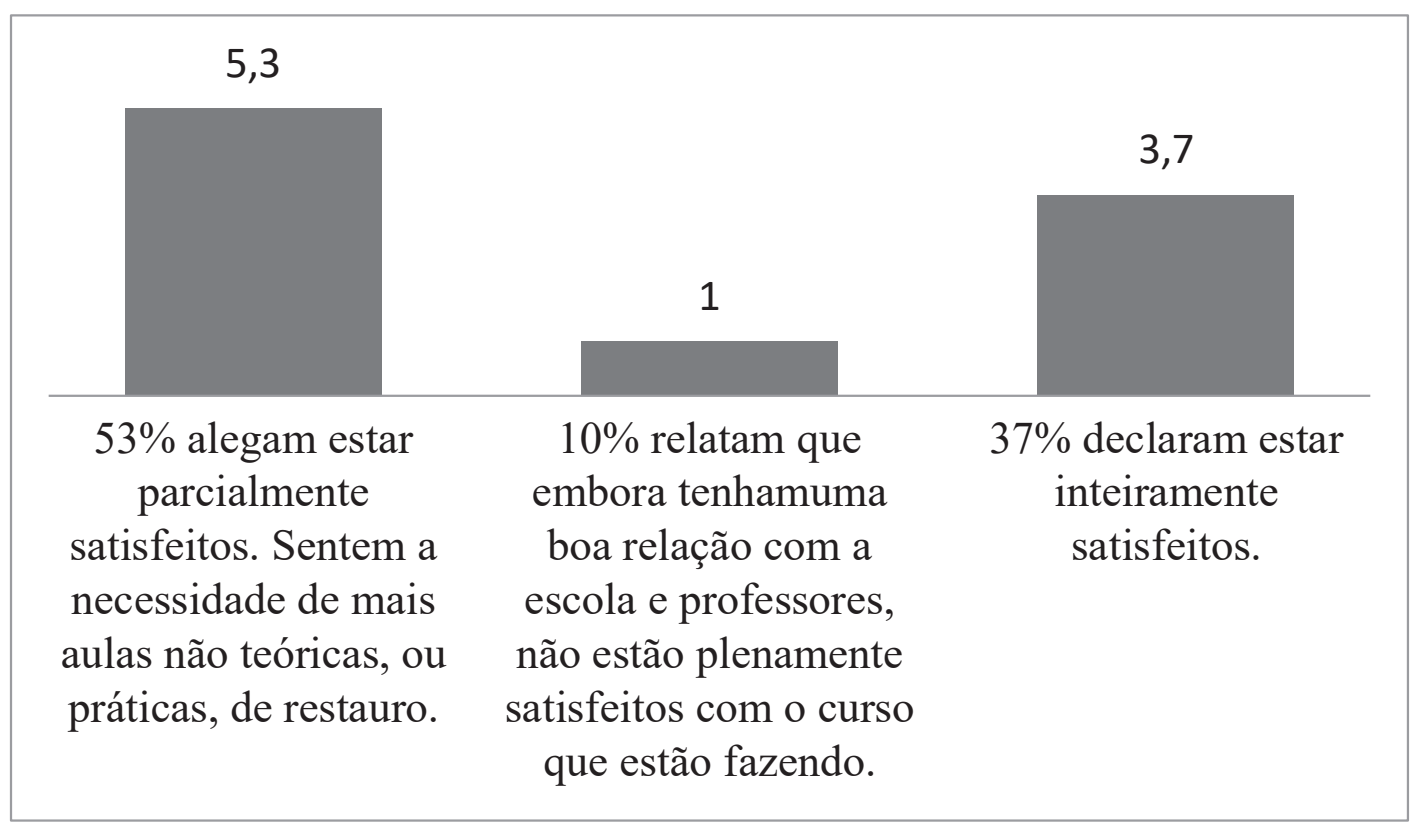

Fonte: própria pesquisa.

O total de $63 \%{ }^{4}$ é preocupante, uma vez que se refere a um universo reduzido de alunos, ou seja, 26. Isto representa que há 17

4 Parcialmente satisfeitos (53\%) somados a insatisfeitos (10\%).

146 Revista Educação e Emancipação, São Luís, v. 9, n. 3, ed. especial, jul./dez. 2016. 
alunos que, embora estejam integrados com o ambiente escolar, podem ser fortes candidatos à evasão. Sobre essa questão, pode-se fazer uma correlação com os conceitos apresentados por Charlot (2005), no que diz respeito à relação que cada aluno constrói com o saber, pois, segundo ele, é essa relação que determinará o fracasso ou o sucesso escolar: assim, não basta apenas estar integrado à escola e aos professores, mas é preciso que o aluno construa uma relação com o saber que possibilite sua permanência e o êxito acadêmico.

No que tange à questão aberta referente ao que os alunos almejam alcançar por meio da formação, eles mencionaram aspectos como "ascensão profissional e pessoal" ou "qualificação na área de atuação", uma vez que muitos já trabalhavam em canteiros de obras antes do curso. Para esta discussão, Charlot (2005) aponta que um percentual de aproximadamente $80 \%$ dos alunos frequenta a escola para mais tarde ter um bom emprego e a possibilidade de uma vida normal:

É uma questão de realismo [...] para se ter um bom emprego, se deve ter um diploma e, para se ter um diploma, se deve passar de uma série para outra. Deve-se ter diploma para ter emprego, deve-se ter emprego para ter dinheiro, e deve-se ter dinheiro para ter uma vida normal (CHARLOT, 2005, p. 67).

Com relação ao item "sugestões", os alunos recomendaram a continuidade dos cursos de Proeja no IFSul, contudo com o aumento da carga horária prática no que tange à parte técnica, bem como à diminuição da rotatividade de professores devido aos afastamentos docentes para qualificação, o que ocasiona grande número de contratação de professores substitutos que, segundo os alunos pesquisados, prejudica o processo de ensino-aprendizagem.

Destaca-se aqui que o estudante no processo de sua formação profissional necessita adquirir expertise na área em que irá atuar. Não há possibilidade de obter êxito nas atividades laborais quando lhe é obstruída, de alguma forma, a formação prática. Não se trata de uma formação pragmática, porém permeada pela teoria e prática. 
O artigo 36 da LDB 9.394/96 dispõe como uma das finalidades do ensino: "[...] a compreensão dos fundamentos científico-tecnológicos dos processos produtivos, relacionando a teoria com a prática, no ensino de cada disciplina" (BRASIL, 1996). Diante do texto legal, compreende-se que o ensino teórico deva estar, necessariamente, atrelado à prática, para que a formação deste profissional seja consolidada satisfatoriamente.

Os alunos sugeriram também mais utilização dos recursos de Tecnologia da Informação e Comunicação (TICs) durante as aulas, o que propiciaria uma aprendizagem mais consolidada e efetiva.

\section{Das aulas práticas à formação do aluno}

De posse dos dados empíricos, foi possível observar que as aulas práticas se configuram como um dos mecanismos mais importantes durante a formação profissional, contudo os próprios alunos apontam a prática prevista como insuficiente, a ponto de solicitarem a ampliação das aulas práticas dessa área de estudo.

Diante deste dado, foi analisado o projeto do curso técnico em Execução, Conservação e Restauro com vistas a verificar os pontos que tratavam das aulas práticas, a fim de que pudesse ser avaliada a execução ou mesmo a necessidade de ser proposta uma ampliação.

Verificou-se a existência de aulas práticas em apenas 8 das 49 disciplinas ofertadas ao longo dos quatro anos de curso. Destacam-se, para apreciação, as duas principais disciplinas (as quais tratam as práticas) para fazer uma análise das ementas propostas. São elas: Materiais, Técnicas e Práticas Construtivas I, II e III; Práticas de Conservação e Restauro I e II. Seguem abaixo as ementas das disciplinas, respectivamente, de acordo com o projeto do referido curso (IFSUL, 2013):

Materiais, Técnicas e Práticas Construtivas I, II e III:

Estudo e experimentação dos materiais simples e compostos utilizados em técnicas construtivas ao longo da história das construções. Estudo e experimentação dos procedimentos e práticas 
aplicados à execução das técnicas construtivas atuais e de períodos relevantes da história da cidade e região. Estudo e experimentação dos materiais, técnicas e práticas construtivas como fundamentos para a conservação e restauro do patrimônio edificado. Estudo das manifestações patológicas das construções. Estudo dos procedimentos aplicados à elaboração de diagnósticos e procedimentos destinados aos reparos dos problemas nas edificações. Estudo dos procedimentos aplicados à manutenção e conservação das edificações históricas da cidade e região.

Práticas de Conservação e Restauro I e ll:

Identificação e estudo dos processos de deterioração que interferem nas edificações e de medidas para possibilitar o prolongamento do tempo de vida do patrimônio edificado. Estudo e experimentação dos materiais, técnicas e práticas construtivas como fundamentos para a conservação e restauro do patrimônio edificado. Identificação de conceitos, critérios e técnicas de conservação e restauro dos elementos construtivos do patrimônio edificado.

Pela análise das ementas acima destacadas, foi possível constatar que a da disciplina de Materiais, Técnicas e Práticas Construtivas I, II e III, embora preveja experimentação prática, traz em si questões bastante teóricas. Já a da disciplina de Práticas de Conservação e Restauro I e II prevê mais especificamente a experimentação dessas práticas e técnicas de aplicação dos conceitos referentes ao restauro e à conservação de patrimônios propriamente ditos.

Ao se analisar a matriz curricular proposta no projeto do curso, foi possível auferir, ao final do período, um quantitativo de 335 horas de carga horária prática e um total de 2.290 horas de aulas teóricas, totalizando 2.625 horas de curso entre teoria e prática. Uma relação no mínimo díspare: $87,24 \%$ teórica x 12,76\% prática. Esse levantamento traz em si questões bastante complexas, já que a carga horária prática corresponde a um percentual ínfimo da carga horária total do curso. E mais: o estágio curricular, de acordo com o projeto, não é componente 
curricular obrigatório, o que remete, mais uma vez, a possíveis fragilidades em relação à formação destes profissionais.

Nos dados levantados ao longo desta investigação, os alunos apontam para a necessidade de ampliação das práticas durante sua formação. Quando o projeto do curso é analisado, verifica-se a carência apontada por eles, o que vem a colaborar para a necessidade de uma (re) estruturação do Projeto Pedagógico.

Como se observa, as questões abalizadas se tornam ainda mais preocupantes quando busca aliar as reflexões propostas em documentos norteadores, tais como o Catálogo Nacional de Cursos Técnicos, que traça o perfil profissional de conclusão do egresso do curso em Conservação e Restauro: o egresso deste curso, conforme o referido catálogo, deverá ser um profissional que "realiza processos de conservação e restauro de peças do patrimônio histórico e cultural. Aplica técnicas materiais e processos de conservação e restauro de acordo com o tipo de bem (pintura, escultura, gravura, desenho, documento, mobiliário e têxtil)" (BRASIL, 2014, p. 107).

Com base nesse documento, ocorre a seguinte reflexão: como o profissional, egresso do IFSul, poderá exercer sua atividade laboral de forma satisfatória, uma vez que em sua formação obteve mais conhecimentos teóricos que práticos? Responde-se ao questionamento fundamentados no Parecer CNE/CEB no 16/99, que trata das diretrizes nacionais para os cursos técnicos de nível médio, e aponta para a necessidade das práticas quando menciona que "[...] os conhecimentos [...] apenas no plano intelectual [são] inúteis como orientadores das práticas humanas" (BRASIL, 1999, p. 24).

Somada ao parecer, a Lei n० 9.394/96 regulamenta as diretrizes e bases da educação nacional. Em seu artigo 35, aponta que uma das finalidades do ensino médio dentro da educação profissional é a de contribuir para "[...] o desenvolvimento da autonomia intelectual e do pensamento crítico; a compreensão dos fundamentos científicotecnológicos dos processos produtivos, relacionando a teoria com a prática, no ensino de cada disciplina" (BRASIL, 1996, n.p.). Visualiza- 
se, dessa forma, que a realidade do projeto do curso, no esboço de sua matriz curricular, não condiz com a previsão legal, fragilizando a estrutura traçada.

Portanto, não se poderia deixar de destacar, com base nos dados obtidos, bem como na relação com os fundamentos teóricos e legais citados ao longo deste estudo, a necessidade de uma reestruturação curricular, de forma que possibilite aos egressos do referido curso uma formação sólida que vincule conhecimentos teóricos aos práticos, permitindo a formação integral deste profissional.

\section{Considerações finais}

No desfecho desta análise inicial, consideram-se o histórico da EJA no Brasil, o percurso da educação profissional e tecnológica em Pelotas e os dados provenientes da pesquisa, chegando à conclusão de que a proposta inicial foi mantida, porém, da forma como vem se constituindo, necessita ser (re)construída e (re)avaliada para atender tanto aos dispositivos legais quanto aos anseios dos alunos.

Percebeu-se ainda que, apesar das constantes trocas nominais sofridas pela instituição (atualmente denominada Instituto Federal sul-rio-grandense - IFSul), e considerando as distintas reestruturações curriculares que se sucederam ao longo do caminho, a oferta da EJA pelo Campus Pelotas - mesmo que tenha permitido que os alunos aprendessem conteúdos referentes a cada nível de aprendizagem necessita de uma (re)organização curricular, uma caracterização mais específica do perfil do egresso, para que o docente possa se planeja com vistas aos anseios deste adulto que retorna à escola, buscando uma formação acadêmica e profissional.

Destaca-se a fragilidade da constituição de um curso de formação profissional no qual as aulas práticas estão longe do cotidiano do aluno: a falta de uma prática mais próxima desta formação enfraquece a atuação e a inserção destes profissionais no mercado de trabalho. Contudo, verifica-se que a implantação do Proeja demonstra 
um alto comprometimento das instituições públicas com a educação, permitindo e assegurando a muitos cidadãos o direito de retornarem aos bancos escolares e que o IFSul, enquanto instituição de ensino pública, cumprindo seu papel como tal, tem oportunizado esse acesso a muitas pessoas.

Conclui-se, inicialmente, que ainda há muitas questões a serem aprimoradas e que esta pesquisa poderá servir como ponto de partida para repensar o curso e seus objetivos. Inclusive sugere novas propostas curriculares, tendo como base os percentuais de satisfação e insatisfação apresentados.

Destarte, diante dos dados coletados e analisados, infere-se que o Proeja no IFSul, Campus Pelotas, não vem cumprindo a contento com os objetivos que se propõe no projeto do curso, pois tal projeto prevê que o curso técnico em Execução, Conservação e Restauro de Edificações será capaz de promover a "[...] formação de um cidadão crítico, autônomo, com capacidade de ação social e de, a partir de seu trabalho, construir sua própria emancipação" (IFSUL, 2013, p. 8).

Observa-se que a formação deste trabalhador, da maneira como vem se efetivando, não propicia a sua inserção no mercado de trabalho - uma vez que não há um equilíbrio entre os conhecimentos teóricos e práticos, dificultando a partir de seu trabalho a sua emancipação. Há carência de formação específica no ofício a que ele pretende adquirir.

Contudo, ele se destaca no que tange a "assegurar a jovens e adultos, excluídos do sistema formal de educação, uma oportunidade de educação profissional técnica de nível médio numa área - a construção civil - reconhecida por possuir grande número de trabalhadores com baixa escolaridade" (IFSul, 2013, p. 8). Assim, o IFSul vem desenvolvendo um importante trabalho, mesmo com a necessidade de (re) posicionamentos no âmbito da profissionalização do estudante, dentro do Proeja, ofertando formação acadêmica e profissional a muitos jovens e adultos que almejavam esse retorno aos bancos escolares. 


\section{Referências}

BEISIEGEL, C. de R. Política e educação popular. 2. ed. São Paulo: Ática, 1989.

BRASIL. Constituição da República dos Estados Unidos do Brasil de 1934. 1934. Disponível em: <http://www.planalto.gov.br/ccivil_03/ Constituicao/Constituicao34.htm>. Acesso em: 18 mar. 2016.

Lei n $^{\circ}$ 4.024/61, de 20 de dezembro de 1961. Fixa as Diretrizes e Bases da Educação Nacional. Diário Oficial [da] República Federativa do Brasil, Brasília, 20 dez. 1961. Disponível em: <http://www2.camara. leg.br/legin/fed/lei/1960-1969/lei-4024-20-dezembro-1961-353722publicacaooriginal-1-pl.html>. Acesso em: 08 abr. 2016.

. Constituição Federal de 1988. 1988. Disponível em: <http:// www.planalto.gov.br/ccivil_03/Constituicao/Constituicao.htm>. Acesso em: 18 mar. 2016.

. Lei n 9.394/96, de 20 de dezembro de 1996. Estabelece as diretrizes e bases da educação nacional. Diário Oficial [da] República Federativa do Brasil, Brasília, DF, 20 dez. 1996. Disponível em: <http:// www.planalto.gov.br/ccivil_03/leis/L9394.htm>. Acesso em:08 abr. 2016.

- Diretrizes curriculares nacionais para a educação profissional de nível técnico: Parecer CNE/CEB 16/1999. 1999. Disponível em: <http://portal.mec.gov.br/cne/arquivos/pdf/1999/ pceb016_99.pdf>. Acesso em: 18 mar. 2016

Diretrizes curriculares nacionais para a educação de jovens e adultos: Parecer CNE/CEB 11/2000. 2000. Disponível em: <http:// mobile.cnte.org.br:8080/legislacao-externo/rest/lei/68/pdf>. Acesso em: 15 mar. 2016.

- Ministério da Educação. Secretaria de Educação Profissional e Tecnológica. Catálogo nacional de cursos técnicos. Brasília, 2014. Disponível em: <http://www.dept.cefetmg.br/galerias/arquivos_ download/RESOLUCOES_CEPT/2014/CATACATA_2014.pdf>. Acesso em: 02 abr. 2016. 
. Ministério da Educação. Centenário da rede federal de educação profissional e tecnológica. 2011. Disponível em: <http:// portal.mec.gov.br/setec/arquivos/centenario/historico_educacao_ profissional.ppd>. Acesso em: 29 mar. 2016.

CHARLOT, B. Relação com o saber, formação de professores e globalização: questões para a educação hoje. Porto Alegre: Artmed, 2005.

DENZIN, N.; LINCOLN, Y. S. O planejamento da pesquisa qualitativa: teorias e abordagens. 2. ed. Porto Alegre: Artmed, 2006.

DIAS, D.; SILVA, M. F. Como escrever uma monografia: manual de elaboração com exemplos e exercícios. São Paulo: Atlas, 2010.

FAVERO, O. Uma perspectiva da participação popular: análise da prática educativa do MEB - Movimento de Educação de Base (1961/1966). Campinas: Autores Associados, 2006.

FREIRE, P. Pedagogia da Autonomia. In: Saberes necessários à prática educativa. São Paulo: Paz e Terra, 1996.

GASPAR, L. Movimento de cultura popular. Recife: Fundação Joaquim Nabuco, 2009. Disponível em: <http://basilio. fundaj.gov.br/pesquisaescolar.\%20/index.php?option $=$ com content\&view=article\&id=723\&ltemid=191 >. Acesso em: 18 mar. 2016.

HENN, L. G.; NUNES, P. P. C. A educação escolar durante o período do Estado Novo. Revista Latino-Americana de História, v. 2, n. 6, ago. 2013. Disponível em: <http://projeto.unisinos.br/rla/index.php/rla/ article/viewFile/254/207>. Acesso em: 8 abr. 2016.

IFSUL. Instituto Federal de Educação, Ciência e Tecnologia sul-riograndense. Diretoria de Ensino. Projeto do curso técnico em Execução, Conservação e Restauro de Edificações. Pelotas: [s.n.], 2013.

LINDEMAN, E. C. The meaning of adult education. New York: Northeastern University, 1926. Disponível em: <https://archive.org/ details/meaningofadulted00lind >. Acesso em: 11 abr. 2016. 
MEIRELES, C. M. da S. Das artes e officios à educação tecnológica: 90 anos de história. Pelotas: UFPEL, 2007.

PAIVA, V. História da educação popular no Brasil: educação popular e educação de adultos. 6. ed. São Paulo: Loyola, 200 